\title{
Uma abordagem funcional dos advérbios e adverbiais de tempo e aspecto em relatos
}

\section{A functional approach about the adverbs and adverbials of time and aspect on reports}

\author{
Jhonathan Leno Reis França Santana ${ }^{1}$ \\ Gesieny Laurett Neves Damasceno ${ }^{2}$
}

Resumo: Este artigo objetiva analisar e descrever o comportamento de advérbios e adverbiais de tempo e aspecto, sob a ótica dos processos de divergência (HOPPER, 1991), em reportagens acerca de relatos de violência homofóbica, veiculadas por jornais de circulação online. $\mathrm{O}$ tratamento dispensado aos dados foi de natureza holística, seguindo a tendência das pesquisas funcionalistas nas quais a pesquisa se ancora (MARTELOTTA, 2009; 2012; CASTILHO et al., 2014), a fim de que se pudesse efetuar o estudo descritivo desses elementos adverbiais. A investigação revelou, dentre outros aspectos, que a relação semântica mais realizada pelos advérbios/adverbiais de tempo é a de localização temporal definida do evento (80\%) e já no que tange aos aspectuais, a relação mais presente foi a de duração do evento (46,8\%). Alguns circunstanciadores, em menor proporção, apresentaram um ingrediente de foricidade, atuando na cadeia coesiva do texto.

Palavras-chave: Advérbios. Funcionalismo. Relato.

Abstract: This article aims to analyze and describe the behavior of adverbs and adverbials of time, from the perspective of divergence processes (HOPPER, 1991), in reports of homophobic violence in online newspapers. The treatment given to the data was of a holistic nature, following the trends of functionalist research (MARTELOTTA, 2009; 2012; CASTILHO et al., 2014) so these adverbial elements could undergo a descriptive study. Among others aspects, the investigation revealed that the semantic relation most performed by adverbs/adverbials of time is the definite temporal location of the event (80\%). Regarding the aspectuals, the most present relationship was the duration of the event $(46,8 \%)$. Some circumstanceers, to a lesser extent, presented an ingredient of foricity, acting in the cohesive chain of the text.

Keywords: Adverbs. Functionalism. Report.

\footnotetext{
${ }^{1}$ Universidade Federal do Espírito Santo, Programa de Pós-Graduação em Linguística, Vitória, ES, Brasil. Bolsista da FAPES. Endereço eletrônico: 1y_leno@ @otmail.com.

${ }^{2}$ Universidade Federal do Espírito Santo, Centro de Ciências Humanas e Naturais, Departamento de Línguas e Letras, Programa de Pós-Graduação em Linguística, Vitória, ES, Brasil. Endereço eletrônico: gesieny@yahoo.com.br.
} 


\section{Considerações iniciais}

Este artigo propõe-se a realizar um estudo funcional acerca dos advérbios e adverbiais de tempo e aspecto, no que tange à ampliação do escopo dessas palavras e arranjos de palavras para outros escopos que não o de localização temporal da ação verbal, tradicionalmente compreendida como a principal função desses elementos (como adendo, a tradição compreende que os advérbios de intensidade podem incidir sobre o grau de adjetivos e advérbios). Em outras palavras, investigam-se os processos de divergência (HOPPER, 1991), definidos pelo estudioso como o resultado da convivência, no sistema linguístico, de "pares ou múltiplas formas que possuem uma etimologia comum, mas que divergem

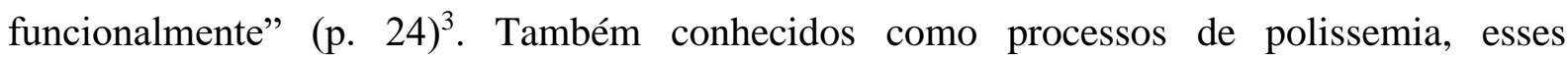
fenômenos indicam a possibilidade de mudanças linguísticas no curso da evolução de uma língua natural, bem como a convivência, numa dada sincronia, de elementos linguísticos que, embora apresentando a mesma forma, exercem funções em diferentes níveis linguísticos, realizando assim distintos significados. Nesse rol, incluem-se os advérbios de tempo e aspecto, que podem operar tanto no nível oracional, quanto no nível textual-discursivo, como veremos a seguir.

Contudo, antes de iniciar-se o estudo do fenômeno, é necessário discutir no âmbito teórico o que tal empreendimento tem a acrescentar às conquistas já estabelecidas no arcabouço de conhecimentos acerca da linguagem, mais precisamente, no que concerne aos conhecimentos assentados em várias gramáticas da tradição, ao longo dos séculos, os quais devem ser retomados a fim de que se compreenda o que esta proposta de análise dos elementos circunstanciais de tempo e aspecto tem a acrescentar.

Nos primórdios da reflexão ocidental acerca da linguagem, a razão ática voltou-se para a querela do naturalismo versus convencionalismo dos nomes ${ }^{4}$. Dessa disputa, nasceu a doutrina das partes do discurso, a partir da influência do Organon aristotélico (NEVES, 2012). Essa doutrina lançou as sementes que resultaram na produção massiva de gramáticas e dicionários, que do século V ao XVI pode ser constatada no continente europeu. Ganha destaque o fato de que o modelo de gramática proveniente das colônias gregas serviu de base para a facção não só de gramáticas das línguas indo-europeias, mas também de línguas ameríndias e semíticas, chegando até os dias atuais como o paradigma linguístico de maior aplicação e prestígio social. Nesse sentido, pode-se justificar a relevância de investigar nas

\footnotetext{
${ }^{3}$ Livre tradução de "pairs or multiplex of forms having a common etymology, but diverging functionally" (HOPPER, 1991, p. 24).

${ }^{4} \mathrm{O}$ diálogo Crátilo, escrito por Platão, é considerado a obra marco dessa discussão, no âmbito da filosofia.
} 
gramáticas normativas o que elas têm a dizer sobre os elementos adverbiais, bem como, sem a intenção de negar os seus sucessos, apontar seu alcance analítico no que concerne ao tratamento do fenômeno.

Justifica-se a escolha desse objeto de estudo com base na constatação de que a natureza fluida da categoria dos advérbios ocasiona que processos generalizados de divergência concorram para a efetivação das necessidades contingenciais do uso linguístico, o que resulta na ampliação do escopo de atuação dos elementos situados na categoria, fazendoos operar nos níveis intra-oracional (localizando o evento no tempo ou marcando a sua duração/frequência), interoracional (funcionando como operadores discursivos) e textual (com função argumentativa e fórica). Além de operar nesses níveis, esses elementos podem incidir sobre uma oração sem necessariamente lhe integrar, sintaticamente, a estrutura, situando no tempo todo o conteúdo da proposição ou indicando sua frequência, duração, reiteração e/ou quantificação. Portanto, investiga-se em que medida os processos de divergência estão afetando o escopo de atuação dos elementos circunstanciais de tempo e aspecto, no que tange aos aspectos distribucionais (em relação ao núcleo $\mathrm{SV}$ ), semânticos (referente às nuances temporais que esses advérbios expressam) e textuais (aqui, especificamente, referindo-se ao conteúdo de foricidade que certas construções apresentam).

O recorte analítico consiste de quatro reportagens coletadas em sites de circulação online, que têm como foco apresentar relatos de vítimas de violência homofóbica. A escolha do corpus justifica-se pelo fato de os relatos apresentarem um caráter marcadamente narrativo, característica que contribui para a presença significativa de circunstanciais temporais e aspectuais.

Em primeira instância, a observação cuidadosa do material suscitou as seguintes hipóteses: (i) o grupo dos advérbios/adverbiais de tempo e aspecto apresenta-se como uma subcategoria fluida, pois a funcionalidade de seus elementos pode atuar desde o nível oracional até o nível discursivo; (ii) O comportamento dos advérbios e adverbiais de tempo e aspecto não permite que sua definição se dê em termos de propriedades inerentes, mas, a partir do tipo de relação que tece (CASTILHO et al., 2014); (iii) os elementos circunstanciais aspectivos apresentam maior fluidez comportamental do que os circunstanciais de tempo.

O percurso metodológico consistiu em quatro etapas. A primeira teve por foco realizar um estudo detalhado de três gramáticas normativas da língua portuguesa (ROCHA LIMA, [1972]2000); CUNHA; CINTRA, [1985]2007; HAUY, 2015). Trabalhou-se com essas gramáticas de forma esquemática, com a construção de tabelas que permitissem uma visualização panorâmica dos fatos. A seguir, selecionou-se o material para análise. 
Selecionado o material, buscou-se analisá-lo com base na doutrina encontrada nessas gramáticas. Após constatar-se o limite da proposta tradicional, que não pôde explicar a atuação de advérbios e adverbiais que tomam como escopo todo o conteúdo da proposição, nem daqueles que se relacionam com porções maiores do texto, realizou-se um levantamento detalhado de pesquisas funcionalistas sobre o tema. Essas investigações revelaram-se extremamente eficientes para o tratamento do problema, o que motivou uma segunda análise, agora, com base no instrumental funcionalista. Essa segunda análise demonstrou-se bastante eficiente para o tratamento dos fenômenos que as três gramáticas da tradição não puderam explicar. Em face disso, constatou-se a necessidade de diálogo entre ambos os campos, o que motivou a realização deste empreendimento.

\section{Os advérbios sob a ótica do Paradigma Tradicional de Gramatização}

Esta seção tem por meta discutir o conceito de Paradigma Tradicional de Gramatização (VIEIRA, 2018). Para isso, foram investigadas três gramáticas normativas da língua portuguesa, desenvolvidas no Brasil, a saber: Gramática Normativa da Língua Portuguesa, de Carlos Henrique da Rocha Lima ([1972]2000), Nova Gramática do Português Contemporâneo, de Celso Cunha e Lindley Cintra ([1985]2007) e Gramática Padrão da Língua Portuguesa, de Amini Boainain Hauy (2015).

Os objetivos são (i) discutir o alcance, no que concerne à classe dos advérbios, da proposta do Paradigma Tradicional de Gramatização (doravante, PTG), e (ii) verificar se essas obras dispensam um tratamento homogêneo ao fenômeno, tanto do ponto de vista da doutrina gramatical quanto de sua dimensão ideológica.

\section{PTG: a proposta}

Utilizando-se do conceito de gramatização de Auroux (1992) - noção que busca compreender a produção massiva de gramáticas de diferentes línguas, embasada na tradição greco-latina, e identificada pelo estudioso como uma segunda revolução técnico-linguística (a primeira se deu com o aparecimento dos primeiros sistemas de escrita), Vieira (2018) desenvolve o conceito de Paradigma Tradicional de Gramatização (PTG), a partir da ampliação temporal em relação ao período analisado por Auroux. O linguista considera

[...] a elaboração de instrumentos de gramatização tanto no período da segunda revolução técnico-linguística - marcado pelo progressivo declínio do latim e pela ascensão, desenvolvimento e consolidação dos vernáculos 
europeus como línguas de cultura escrita - quanto em épocas anteriores e posteriores (VIEIRA, 2018, p. 10).

A origem do PTG deu-se nas colônias gregas, durante o período helenístico, quando os primeiros filólogos, embasados nas reflexões filosófico-linguísticas do pensamento helênico, deram início à produção das primeiras reflexões acerca da forma correta de utilização do dialeto ático, assim como dos primeiros manuais de retórica.

No tocante à linguagem, há que se considerar a forma como os pensadores gregos the dispensaram tratamento. Para tal, distinguem-se dois períodos: o helênico, período da produção filosófico-literária grega, e o helenístico, período que sucedeu ao helênico, voltado para a valorização e reflexão acerca das conquistas do período anterior. Foi desse último período que vieram as primeiras gramáticas (NEVES, 2012).

Para Neves (2012), compreender o esforço linguístico realizado pelos filólogos alexandrinos significa falar "de 'visão de gramática' na 'vivência da linguagem"” (2012, p. 25). Em termos linguísticos, isso representa um trabalho metalinguístico sobre a experiência, socialmente situada, de uso da linguagem. Como motivação para que tal esforço tivesse início, Neves (1987) cita a necessidade que esses primeiros filósofos sentiram de preservar a linguagem literária sobretudo frente à corrupção - eles acreditavam que os diferentes registros de uso coloquial vinham deturpando a pureza da língua de Homero - que vinha sofrendo o dialeto ático (o dialeto de maior prestígio social, tendo sido falado em Atenas).

É exatamente essa postura protetiva em relação a uma linguagem considerada superior, pura, ideal, modelar, que Vieira (2018) constata como presente em todos os momentos históricos em que se produziram gramáticas normativas. É, principalmente, esse conteúdo socioideológico que perpassa o fazer de todos os gramáticos ao longo da história do paradigma. Contudo, Vieira (2018) reconhece que no campo propriamente doutrinário, muitas são as querelas e posturas adotadas. Nesse sentido, não se pode afirmar que o PTG se configura como um campo homogêneo, ao contrário, é extremamente complexo. As três gramáticas aqui investigadas comprovam isso. Embora o cerne da doutrina seja o mesmo, há muitas nuances e discordâncias, inclusive no caso dos advérbios, como será demonstrado abaixo.

Quando se utiliza, portanto, o conceito de PTG, refere-se ao conteúdo socioideológico supracitado, sem que isso signifique considerar as gramáticas como homogêneas do ponto de vista doutrinário. Além disso, preferiu-se o rótulo gramática tradicional ao rótulo gramática normativa, pois, como no caso de Hauy (2015), algumas obras, embora inseridas nesse 
paradigma teórico, não apresentam uma tendência prescritivista. Outros casos há, como o de Rocha Lima ([1972]2000), em que o autor, embora assuma um posicionamento normativo, o faz com base em doutrina divergente em relação à Nomenclatura Gramatical Brasileira (NGB). Por último, há os autores, como Cunha e Cintra ([1985]2007), que se detêm na proposta da NGB.

\section{A classe dos advérbios segundo Rocha Lima ([1972]2000)}

Para Rocha Lima ([1972]2000), os advérbios são palavras que modificam o verbo, apresentando as circunstâncias através das quais a ação se desenrola. Sob o critério morfológico, o gramático considera essas palavras como sendo invariáveis - mesma posição das outras duas obras analisadas neste artigo -, todavia, sintaticamente, há duas possibilidades para a atuação desses elementos, na posição assumida por Rocha Lima ([1972]2000): (i) funcionam como complementos circunstanciais, portanto, como argumentos do verbo, o que os coloca, quando exercendo essa função, entre os chamados Termos Integrantes; (ii) funcionam como adjuntos adverbiais, o que os coloca, quando exercendo essa função, entre os chamados Termos acessórios.

É importante destacar que esse gramático se opõe, muitas vezes, à proposta da NGB, inclusive no que concerne à classe dos advérbios, visto que a classificação que sua gramática apresenta para os itens dessa categoria discorda da classificação assentada na nomenclatura oficial. Essa constatação situa-o no polo dos gramáticos tradicionais não seguidores da NGB.

Rocha Lima ([1972]2000) reconhece a existência de palavras que indicam afirmação (sim, certamente, com efeito), negação (não, qual nada), exclusão (só, apenas, exclusive), inclusão (também, mesmo), avaliação (quase, mais ou menos), designação (eis), explicação (como, a saber), retificação (aliás, ou melhor) etc., mas afirma que elas não representam circunstâncias, e por isso não poderiam ser incluídas na classe dos advérbios. A razão para a exclusão desse conjunto de palavras do inventário de advérbios da língua portuguesa é a incidência, que pode se dar para além dos verbos, adjetivos e advérbios, como, por exemplo, a partícula não, que pode negar uma parte da oração, ou ela inteira.

Por fim, o que hodiernamente em linguística denomina-se advérbios modalizadores, Rocha Lima ([1972]2000) classificará sob o rótulo de Palavras Denotativas (certamente, só, apenas, aliás, ou melhor). Como razão para a exclusão dessas palavras da classe dos advérbios, o gramático afirma que fazem referência ao sujeito do enunciado, o que impede de classificá-las como advérbios. 


\section{A classe dos advérbios segundo Cunha e Cintra ([1985]2007)}

Na definição apresentada por Cunha e Cintra ([1985]2007), os advérbios são, fundamentalmente, um modificador do verbo. No entanto, a essa função básica, certos advérbios acrescentam outras que lhe são privativas, como é o caso dos chamados advérbios de intensidade que, de acordo com os autores, podem reforçar o sentido de um adjetivo ou, ainda, de um advérbio.

Diferentemente de Rocha Lima ([1972]2000), que concebe a possibilidade de os advérbios funcionarem como complementos circunstanciais (portanto, como argumentos do verbo - Termos Integrantes), para Cunha e Cintra ([1985]2007), esses elementos são indistintamente adjuntos, ou seja, Termos Acessórios, que apenas delimitam as circunstâncias da ação.

A obra de Cunha e Cintra ([1985]2007), intitulada Gramática do Português Contemporâneo, está situada entre os compêndios seguidores da NGB - o que se confirma, por exemplo, na classificação apriorística adotada para os advérbios, que é a mesma presente naquele documento oficial: a) advérbios de afirmação (sim, certamente, realmente etc.); b) advérbios de dúvida (porventura, possivelmente, provavelmente etc.); c) advérbios de intensidade (assaz, bastante, muito etc.); d) advérbios de lugar (abaixo, acima, junto etc.); e) advérbios de modo (assim, melhor, pior etc.); f) advérbio de negação (não) e g) advérbios de tempo (agora, ainda, tarde etc.).

Tal como Rocha Lima ([1972]2000), Cunha e Cintra ([1985]2007) utilizam a denominação Palavras Denotativas. Todavia, as estruturas linguísticas alocadas sob esse rótulo não são as mesmas. De acordo com Cunha e Cintra ([1985]2007), certas palavras, por vezes, foram enquadradas impropriamente entre os advérbios - palavras essas que denotam inclusão (até, mesmo, também etc.), exclusão (apenas, salvo, somente etc.); designação (eis); realce (cá, lá, é que etc.); retificação (aliás, isto é, ou melhor etc.) e situação (afinal, agora, mas etc.). De acordo com Cunha e Cintra ([1985]2007), tais palavras não devem ser incluídas entre os advérbios, visto que não modificam o verbo, nem o adjetivo, nem outro advérbio.

Quando fazem alusão ao fato de as chamadas palavras denotativas terem recebido classificação à parte pela Nomenclatura Gramatical Brasileira (ainda que sem um nome especial), esses gramáticos permitem entrever que a motivação para a exclusão dessas locuções da classe dos advérbios pauta-se, novamente, na aderência de sua gramática a esse documento oficial. 


\section{A classe dos advérbios segundo Hauy (2015)}

Hauy (2015) compreende, com base em Meier (1973), que o critério morfológico para a distinção entre a categoria de adjetivo e a categoria de advérbio é a variabilidade do primeiro e a invariabilidade do último. Quanto ao funcionamento sintático da classe, a estudiosa afirma que são modificadores do verbo e do adjetivo, "expressando as várias circunstâncias ou matizes que envolvem sua significação, ou intensifica a noção expressa pelo verbo, adjetivo, pronome, advérbio, locução adverbial ou expressão adverbial" (HAUY, 2015, p. 973). É importante notar que a autora inclui uma nova subclasse dentro da classe adverbial, a subclasse das expressões adverbiais. Para Hauy (2015), o que diferencia as expressões adverbiais (antes do início do movimento, naquele dia festivo, com muito pouco entusiasmo) das locuções adverbiais (de repente, a prazo, tintim por tintim) é que as locuções são construções gramaticalizadas que equivalem a um advérbio, funcionando sempre como adjunto adverbial; já as expressões apresentam caráter de contingência, sendo formadas ocasionalmente e apresentando a mesma função acima referida.

Quanto à classificação, a autora adota a que se encontra na NGB. Entretanto, ela recupera discussões de outros gramáticos, como Rocha Lima e José Oiticica, que consideram que os chamados advérbios de afirmação e negação (segundo a NGB) são palavras denotativas, e, portanto, não podem ser incluídas na classe adverbial.

Percebeu-se que a autora busca contemplar tanto a visão da NGB quanto a perspectiva de gramáticos que divergem do documento (ao menos no capítulo acerca dos advérbios), assumindo uma posição que traz à tona as muitas visões integrantes do PTG.

\section{PTG: o que se pode afirmar a partir da análise das três gramáticas}

Algumas questões, de extrema importância para um entendimento claro acerca do tratamento da classe adverbial nas gramáticas tradicionais, guiaram a busca nessas gramáticas pelo cerne de sua doutrina adverbial. São elas:

(i) é possível afirmar que essas gramáticas fazem parte de um mesmo paradigma teórico?

(ii) Se a noção de PTG se aplica a tais gramáticas, isso se dá em que medida?

(iii) Há zonas de divergência no que tange à doutrina adverbial presente nas gramáticas?

(iv) Quando se rotulam tais gramáticas de normativas, o que se deixa muitas vezes de considerar, tendo em vista a especificidade de cada obra que compõe esse conjunto ternário quando cotejadas entre si, no que tange à classe adverbial? 
Inicia-se por afirmar que a dimensão socioideológica de produção dessas gramáticas é a mesma que em épocas anteriores levou gregos e, por influência desses, latinos a escreverem suas gramáticas. A exemplificação sempre embasada nos expoentes do cânone literário, a compreensão estática acerca de suas categorias, a crença de que algumas partes do discurso (leia-se classes de palavras) são mais importantes (Termos Essenciais e Integrantes) que outras (Termos Acessórios, conjunto de que faz parte a classe dos advérbios), tudo isso subjaz à doutrina constatada em cada uma das três gramáticas.

Um procedimento muito útil, utilizado nesse estudo para a compreensão de como os advérbios são tratados nas gramáticas, foi o de contabilizar o espaço que esses compêndios destinam ao tratamento do tema frente ao espaço dispensado para o tratamento de outras classes (que figuram como núcleo e periferias dos termos essenciais e integrantes). Para isso, escolheram-se quatro classes de palavras, que foram consideradas pela Gramática do Português Culto Falado no Brasil como abertas (CASTILHO et al., 2014), pois recebem constantes aportes lexicais em decorrência de novas práticas discursivas. As classes são substantivo, adjetivo, verbo e advérbio. O quadro abaixo realiza um cruzamento entre cada uma das classes (eixo horizontal) e as gramáticas (eixo vertical) no que concerne ao espaço destinado (número de páginas) para o tratamento desses temas:

Quadro 1. Espaço destinado ao tratamento das classes de palavras abertas, em três gramáticas tradicionais do português

\begin{tabular}{|c|c|c|c|}
\hline $\begin{array}{c}\text { GRAMÁTICA / CLASSE } \\
\text { DE PALAVRA }\end{array}$ & $\begin{array}{c}\text { ROCHA LIMA } \\
\text { ([1972]2000) }\end{array}$ & $\begin{array}{c}\text { CUNHA E CINTRA } \\
\text { ([1985]2006) }\end{array}$ & HAUY (2015) \\
\hline SUBSTANTIVO & 26 & 28 & 50 \\
\hline ADJETIVO & 10 & 30 & 30 \\
\hline VERBO & 52 & 162 & 112 \\
\hline ADVÉRBIO & 6 & 14 & 8 \\
\hline
\end{tabular}

Fonte: elaboração própria.

Perceba-se que, em todas as gramáticas, a classe dos advérbios foi a que recebeu menor espaço, sendo seguida pela dos adjetivos - que apresentam um número um pouco maior de páginas na gramática de Rocha Lima ([1972]2000) e aproximadamente três vezes mais nas obras de Cunha e Cintra (1985]2006) e Hauy (2015). Notável é o tamanho do espaço destinado ao tratamento dos substantivos e verbos, respectivamente segunda e primeira classes em número de páginas (no caso dos verbos, a maior diferença, chega-se a dispensar um espaço cerca de dez vezes maior do que o dispensado aos advérbios). 
Interpretou-se essa discrepância com base na distinção entre as palavras que constituem o núcleo dos chamados Termos Essenciais (sujeito e predicado), tidos como necessários para a estrutura da oração, Integrantes (complemento nominal, objetos direto e indireto, e o agente da passiva), termos que se realizam através dos substantivos, pronomes e que completam a significação dos núcleos verbal e nominal, e, por fim, dos Acessórios (adjuntos adnominal e adverbial e aposto), que são considerados como não necessários para a construção da sentença, sendo, portanto, termos considerados dispensáveis, do ponto de vista sintático.

Essa constatação demonstra um desligamento do campo tradicional em relação aos conhecimentos que as pesquisas funcionalistas vêm acrescentando ao legado tradicional acerca dos advérbios. A gramática de Hauy (2015), apesar de ser contemporânea dos empreendimentos funcionalistas mais atuais, limita-se a apresentar, conforme a NGB, o conceito e a classificação dos advérbios sem quaisquer referências às descobertas linguísticas.

Esse desligamento do campo tradicional frente às discussões realizadas pelos estudos linguísticos se afigura um tanto problemático, pois as gramáticas do PTG possuem maior prestígio e aplicação social do que as investigações funcionalistas. Por isso, apontamos a necessidade de que o PTG se abra para os resultados oriundos da ciência linguística, não no sentido de adotar os postulados e posicionamentos de tal ciência, mas, a partir dos axiomas de seu próprio paradigma, busque dar tratamento à heterogeneidade aferida no sistema adverbial da língua portuguesa. Note-se, na tabela a seguir, o espaço (número de páginas) que a Gramática do Português Culto Falado no Brasil reserva para o tratamento da categoria de advérbio (CASTILHO et al., 2014):

Quadro 2 - Espaço destinado ao tratamento das classes de palavras abertas, na Gramática do Português Culto Falado no Brasil

Fonte: elaboração própria.

\begin{tabular}{|c|c|}
\hline Classe de palavra & N. de páginas \\
\hline Substantivo & 52 \\
\hline Adjetivo & 24 \\
\hline Verbo & 178 \\
\hline Advérbio & 78 \\
\hline
\end{tabular}

Perceba-se que, depois dos verbos, a classe que apresenta maior espaço para discussão é a dos advérbios. Isso se dá em função da heterogeneidade funcional e estrutural que constitui a classe, bem como da atitude dos linguistas em buscar um tratamento adequado a essa questão. 
Ao ignorar os avanços da ciência linguística no que se refere ao tema advérbios, o PTG perde em poder analítico e descritivo. Além disso, por embasar a norma linguística de maior prestígio social, é a gramática tradicional o paradigma mais ensinado nas escolas brasileiras, sendo sua doutrina acerca dos advérbios o conhecimento legitimado. Isso pode acarretar deficiências na formação dos discentes, os quais muitas vezes não chegam a compreender a multifuncionalidade dessa classe.

\section{Um tratamento funcionalista para os advérbios e adverbiais de tempo e aspecto}

Nesta seção só serão abordados os conceitos que sejam pertinentes para a análise. Há que se lembrar da existência de ostensivos e aprofundados estudos sobre a categoria dos advérbios, como os de Martelotta $(2009,2012)$, bem como importantes gramáticas produzidas por linguistas, como as de Neves (2000) e Castilho (2010), além do extenso tratamento que essa categoria recebe na Gramática do Português Culto Falado no Brasil (CASTILHO et al., 2014).

Os conceitos abordados estão relacionados com postulados e categorias do funcionalismo que sejam relevantes para o tratamento dos advérbios e adverbiais de tempo e aspecto. Em certa medida, retomam-se trabalhos e propostas que se revelaram muito eficientes para o tratamento do tema. Citam-se, além das que já foram indicadas acima, as investigações de Cezario (2002), Soares e Cezario (2012) e Lopes et al. (2018).

A divisão da seção se dá em duas partes: na primeira, explana-se a fundamentação teórica funcionalista utilizada; na segunda, discute-se o percurso metodológico que possibilitou o estudo dos advérbios e adverbiais de tempo e aspecto.

\section{Advérbios e adverbiais de tempo e aspecto à luz dos pressupostos funcionalistas}

Inicialmente, é importante destacar que a proposta teórica que fundamenta esta pesquisa se assenta, principalmente, nos postulados de Martelotta $(2009,2012)$ - que se fundamentou no princípio da divergência (HOPPER, 1991) para o estabelecimento de sua proposta -, bem como na propositura que CASTILHO et al. (2014) apresentam para o estudo dessa categoria. Outras pesquisas funcionalistas foram consultadas, entretanto, identificou-se que a maior parte desses estudos tem como base o caminho aberto por essas pesquisas pioneiras.

Como defende a tradição, morfologicamente, os advérbios propriamente ditos são palavras invariáveis. Sintaticamente, são satélites (NEVES, 2000) do núcleo verbal, podendo ainda, como no caso dos advérbios de intensidade, ligar-se a adjetivos e outros advérbios. 
Adverbiais são os sintagmas nominais e preposicionados (muitas vezes, na aula de hoje, um dia) que assumem função de advérbios (CASTILHO et al., 2014).

É importante considerar que entre os advérbios prototípicos e os adverbiais, há uma zona indeterminada, "assim como entre os advérbios e os adjetivos, e entre os advérbios e os operadores de discurso" (CASTILHO et al., 2014, p. 267).

Segundo Martelotta (2012), os advérbios aspectuais (e adverbiais) indicam a duração, a frequência, a reiteratividade, a sequencialidade etc. Travaglia (1994, p. 44) afirma que:

Aspecto é uma categoria verbal de TEMPO, não dêitica, através da qual se marca a duração da situação e/ou suas fases, sendo que estas podem ser consideradas sob diferentes pontos de vista, a saber: o do desenvolvimento, o do completamento e da realização da situação. (Grifo do autor)

Por outro lado, a categoria de tempo apresenta o caráter dêitico de localização temporal do evento representado na oração, situando-o na anterioridade, na simultaneidade ou na posterioridade.

Embora apresentem essas diferenças, neste trabalho, considera-se que ambos os grupos integram o domínio do tempo, e por isso, denomina-se o conjunto formado pelos dois grupos de circunstanciadores centrados nos aspectuais. Desse modo, propõe-se a conjunção da perspectiva de Castilho et al. (2014), que vê os elementos dessa categoria como circunstaciadores, com a proposta de Martelotta (2012), que centraliza o grupo nos aspectuais, considerando que "os demais advérbios [...], em tese, se relacionam a eles por processos de mudança linguística, ou que são agrupados como uma categoria, por compartilharem atributos" (LOPES et al., 2018, p. 258).

Outra noção importante e que deve ser considerada para o estudo semântico-discursivo desses circunstanciadores é a noção de relação (CASTILHO et al., 2014). Para os autores, os advérbios e adverbiais operam sobre o tempo através das relações que tecem. Essas relações são tecidas a partir dos usos que os indivíduos fazem dos elementos adverbiais temporais e aspectuais. Esses usos refletem a diversidade de modos pelos quais os indivíduos constroem linguisticamente suas experiências acerca do domínio temporal, revelando heterogeneidade conceptual onde o PTG compreende homogeneidade conceptual. Observando os exemplos abaixo (apresentados pelos autores), pode-se compreender essa noção:

(1) saiu depois das oito (CASTILHO et al., 2014, p. 268). 
(2) uns vinte anos atrás, no Belas Artes, então tinha concertos todos os meses (CASTILHO et al., 2014, p. 268).

No primeiro exemplo, a relação tecida é cronológica, especificamente, expressa anterioridade. Já no segundo, a relação tecida, segundo os autores, é de precedência temporal.

Com base nessas noções e conceitos, desenvolveu-se o esquema de análise. Em referência, especificamente, ao nível semântico, enfoca-se um número bem delimitado de relações com base na observação e interpretação dos dados, as quais serão apresentadas na seção de análise dos dados.

\section{Metodologia}

O tratamento dispensado aos dados foi de natureza holística, seguindo a tendência das pesquisas funcionalistas nas quais essa investigação se ancora. Buscou-se analisar e descrever o funcionamento dos advérbios e adverbiais de tempo e aspecto enfocando os aspectos morfossintáticos, semânticos, textuais e discursivos implicados na dinâmica do fenômeno.

Nesse sentido, o aparato de instrumentos e categorias analíticas foi construído da seguinte forma:

a) Para a análise da ordenação dos elementos adverbiais quando incidem sobre o verbo, recorreu-se à proposta de Lopes et al. (2018), que indica quatro posições possíveis: advérbio-x-verbo - ADV-X-V; advérbio-verbo - ADV-V; verbo-advérbio - V-ADV; verbo$x$-advérbio - V-X-ADV;

b) Para o estudo semântico desse grupo de elementos adverbiais, considerou-se, no que tange aos advérbios e adverbiais de tempo, três tipos de relações possíveis: referência temporal indeterminada, referência temporal determinada e referência dêitica;

c) Para a investigação do funcionamento dos advérbios e adverbiais no nível do texto, analisaram-se os elementos que possuíssem função fórica, ou que atuassem como operadores discursivos.

Para a organização dos dados e sintetização dos resultados da análise, utilizou-se o programa EXCEL, do pacote Windows. Através dessa ferramenta, foi possível mapear as ocorrências com base nos traços categoriais selecionados (citados acima). Foram desenvolvidas tabelas que tiveram por finalidade sintetizar os dados provenientes do cruzamento dessas categorias.

O corpus consiste de quatro reportagens selecionadas na sequência temporal que vai de 2014 a 2019 e que veiculam relatos de vítimas de violência homofóbica. Por terem como 
foco esses relatos, as reportagens apresentam um caráter marcadamente narrativo, tanto quando trazem os relatos das vítimas pela via do discurso direto, quanto quando os narra via discurso indireto. Por essa razão, a presença de circunstanciais temporais e aspectuais é bastante presente, pois são extremamente importantes para a caracterização da cena narrada.

\section{Análise de dados}

Martelotta (2009) e Lopes et al. (2018) são exemplos de pesquisas que abordaram a problemática dos advérbios e adverbiais de tempo e aspecto. Contudo, essas investigações limitaram-se a examinar subgrupos específicos dentro do grupo dos circunstanciadores centrados nos aspectuais, como o dos advérbios terminados em -mente. Neste estudo, ampliamos o foco de análise. Optou-se por observar e descrever a dinâmica funcional - em termos da distribuição dos elementos adverbiais na sentença, de sua configuração semântica e das relações textuais que esses elementos tecem - de quaisquer construções que pudessem ser consideradas pertencentes a esse grupo de circunstanciadores.

A contagem dos advérbios e adverbiais de tempo e aspecto, realizada nas quatro reportagens, resultou num total de 126 ocorrências desses circunstanciadores. A tabela a seguir apresenta como esse total se divide quando tomadas as duas configurações semânticas observadas:

Tabela1 - Divisão do número total de ocorrências com base na semântica do advérbio

Fonte: elaboração própria.

\begin{tabular}{|c|c|}
\hline Natureza Semântica & Ocorrência \\
\hline Aspectual & $47(39,09 \%)$ \\
\hline Temporal & $79(60,90 \%)$ \\
\hline Total & $126(100 \%)$ \\
\hline
\end{tabular}

Como se pode notar, a ocorrência dos circunstanciadores temporais é mais alta do que a dos aspectuais. Depreendeu-se que, por serem compostas de relatos, gênero predominantemente narrativo, a alta incidência dos advérbios e adverbiais temporais nas reportagens deu-se em razão da necessidade de caracterização temporal dos acontecimentos narrados. Como são os temporais os responsáveis por localizar temporalmente o evento, é natural que sejam eles os que mais ocorram nas reportagens. Os trechos a seguir apresentam ocorrências desses elementos adverbiais nos relatos: 
(3) Aos 22 anos fui expulsa da república que morava (mas não saí), aos 32, fui chamada de 'big shoes' por um médico e julgada por uma auxiliar de enfermagem no hospital. (GIUSTI, 2014)

(4) No Dia Internacional de Combate à Homofobia, celebrado nesta terça-feira (17), o NE10 ouviu histórias e depoimentos emocionantes de pessoas que sofreram e ainda sofrem o preconceito da família. (OLIVEIRA; JORGE, 2017)

Outro ponto focalizado está na relação entre o número de advérbios e adverbiais, a semântica do elemento adverbial e o tipo de relação operada. Assim, para os advérbios e adverbiais de tempo, temos os seguintes resultados:

Tabela 2 - Possibilidades de interpretação dos advérbios/adverbiais temporais

\begin{tabular}{|c|c|c|c|}
\hline $\begin{array}{c}\text { SEMÂNTICA DO } \\
\text { ADVÉRBIO/ADVERBIAL }\end{array}$ & $\begin{array}{c}\text { REFERÊNCIA } \\
\text { TEMPORAL } \\
\text { DETERMINADA }\end{array}$ & DÊITICO & $\begin{array}{c}\text { LOCALIZAÇÃO TEMPORAL } \\
\text { DEFINIDA DO EVENTO }\end{array}$ \\
\hline Temporal & $6(7,5 \%)$ & $10(12,5 \%)$ & $63(80 \%)$ \\
\hline Total & \multicolumn{3}{|c|}{$79(100 \%)$} \\
\hline
\end{tabular}

Fonte: elaboração própria.

Nota-se que o tipo de expressão temporal mais realizada foi a de localização temporal definida (63/80\%). Compreende-se que isso se dá em razão do caráter informativo que subjaz às reportagens. A função de estabelecer referências temporais determinadas é essencial para a construção da cena narrada, como se observa no seguinte trecho relatado:

(5) A primeira vez que ela me expulsou de casa foi em 2013. Fui morar em outra cidade com a pessoa que eu estava me relacionando. Nos 15 primeiros dias, ela não me procurou para saber se eu estava vivo. (OLIVEIRA; JORGE, 2017)

Os resultados referentes aos advérbios e adverbiais de aspecto estão apresentados na tabela a seguir:

Tabela 3 - Possibilidades de interpretação dos advérbios/adverbiais aspectuais

\begin{tabular}{|c|c|c|c|}
\hline $\begin{array}{c}\text { SEMÁNTICA DO } \\
\text { ADVÉRBIO/ADVERBIAL }\end{array}$ & $\begin{array}{c}\text { DURAÇÃO DO } \\
\text { EVENTO }\end{array}$ & QUANTIFICAÇÃO & FREQUÊNCIA \\
\hline Aspectual & $22(46,8 \%)$ & $10(21,3 \%)$ & $15(31,9 \%)$ \\
\hline Total & \multicolumn{2}{|c}{$47(100 \%)$} \\
\hline
\end{tabular}

Fonte: elaboração própria. 
Perceba-se que os aspectuais que expressam duração e frequência foram os mais incidentes. Nas reportagens, eles exercem as funções de expressar a duração do que é narrado e indicar sua frequência, respectivamente. Já os de quantificação registraram o período de tempo em que se desenrolaram os fatos, como se vê nos exemplos abaixo:

(6) Ela me deu muita força e também me ajuda a enfrentar o preconceito que vou passar pelo resto da minha vida - duração do evento. (OLIVEIRA; JORGE, 2017)

(7) Geralmente respondo na lata, não deixo quieto - frequência. (GIUSTI, 2014)

(8) Morei três meses com uma amiga - quantificação. (OLIVEIRA; JORGE, 2017)

Quando se analisou a relação entre a semântica do advérbio/adverbial e sua ordenação, excluímos os circunstanciadores que tomassem como escopo toda a oração. Julgou-se que, por não fazerem parte da estrutura da oração, não faria sentido analisar sua posição em relação ao verbo. A tabela a seguir apresenta os resultados desse cotejo (o número total de ocorrências de advérbios como modificadores do verbo foi de 70/55\%):

Tabela 4 - Semântica do advérbio versus ordenação

\begin{tabular}{|c|c|c|c|c|}
\hline SEMÂNTICA DO ADV. & ADV-X-V & ADV-V & V-ADV & V-X-ADV \\
\hline ASPECTUAL & 8 & 9 & 13 & 7 \\
\hline TEMPORAL & 10 & 5 & 8 & 10 \\
\hline Total & $18(26 \%)$ & $14(20 \%)$ & $21(30 \%)$ & $17(24 \%)$ \\
\hline
\end{tabular}

Fonte: elaboração própria.

Percebeu-se que esses circunstanciadores não apresentam uma posição de maior incidência. Na verdade, a distribuição dos dados deu-se de maneira relativamente equilibrada, como podemos observar na tabela acima. Isso revela grande capacidade de mobilidade desses elementos na estrutura da oração.

É importante destacar que, ao abordarmos o aspecto semântico dos advérbios e adverbiais de tempo e aspecto, devemos considerar que esse está estreitamente vinculado ao significado que a forma apresenta no contexto em que ocorre. Por essa razão, uma mesma forma pode assumir diferentes significados. Para o estudo das relações que os advérbios e adverbiais de tempo e aspecto assumiram nas reportagens do corpus, considerou-se, no que tange aos de aspecto, cinco possibilidades de interpretação: (i) o advérbio/adverbial expressa a duração do evento; (ii) o advérbio/adverbial expressa quantificação temporal; (iii) o advérbio/adverbial apresenta caráter reiterativo; (iv) o advérbio/adverbial expressa a 
frequência de ocorrência do evento. Visualizem-se, respectivamente, essas possibilidades interpretativas a partir dos seguintes exemplos:

(9) Mesmo com alguns avanços no que diz respeito a conquistas de direitos, a comunidade LGBT ainda luta, principalmente, pra ser aceita em um lugar onde deveria receber apoio incondicional desde sempre: dentro de casa - os advérbios destacados expressam duração do evento. (GIUSTI, 2014)

(10) Foi bem difícil, acabei terminando esse namoro, e aos 16 acabei saindo de casa por um mês - o adverbial destacado expressa quantificação. (GIUSTI, 2014)

(11) Antes disso, às vezes quando a gente dava um 'selinho', juntava um grupo de meninos em volta, sempre olhando, gente querendo tirar foto - o advérbio expressa reiteratividade. (PEROBELLI, 2016)

(12) Já cansei de ir pra praia e me gritarem 'mocinha', 'madame', 'viadinho'. Toda semana, já até me acostumei - o adverbial expressa a frequência do acontecimento. (FERNANDES, 2019)

Por sua vez, para as construções adverbiais de tempo, consideraram-se três possibilidades de interpretação: (i) o advérbio/adverbial expressa uma referência temporal indefinida; (ii) o advérbio/adverbial apresenta caráter dêitico, apontando para a situação de comunicação; (iii) o advérbio/adverbial expressa uma referência temporal definida. Contudo, cabe salientar que as três possibilidades interpretativas para os advérbios e adverbiais de tempo são perpassadas por um sentido de localização temporal do evento, e que essa é a característica principal desse grupo. Os exemplos abaixo demonstram isso:

(13) Um dia, eu vi dentro da escola meu nome completo pichado na porta do banheiro com palavrões como "viadinho" e ameaças de morte, essas coisas que LGBT sofrem todos os dias - o adverbial expressa uma referência temporal indeterminada. (PEROBELLI, 2016).

(14) Nesta quinta-feira (13/06), o Supremo Tribunal Federal decidiu, por 8 votos a 3, criminalizar a homofobia e a transfobia, considerando que atos preconceituosos contra homossexuais e transexuais devem ser enquadradas no crime de racismo - o adverbial funciona como dêitico, localizando o evento no tempo com base na situação de comunicação. (OLIVEIRA; JORGE, 2017). 
(15) Na última discussão, há cerca de duas semanas, Denner conta que foi agredido pelo pai, mas que não vai desistir de mostrar a eles que não pode mostrar o jeito que é - o adverbial expressa referência temporal definida. (GIUSTI, 2014)

Apenas dois advérbios prototípicos apresentaram uma relação de foricidade, são eles: ainda (7 ocorrências) e novamente (2 ocorrências). Esses advérbios, classificados semanticamente como aspectuais, atuaram no nível da cadeia coesiva, como demonstrado no exemplo abaixo:

(16) As brigas continuaram e, novamente, Denner saiu de lá. (OLIVEIRA; JORGE, 2017)

No exemplo, novamente retoma uma informação já apresentada no parágrafo anterior, expressando o caráter reiterativo do acontecimento. $\mathrm{O}$ trecho a que o advérbio faz referência é "A primeira vez que ela me expulsou de casa foi em 2013. Fui morar em outra cidade com a pessoa que eu estava me relacionando. Nos 15 primeiros dias, ela não me procurou para saber se eu estava vivo" (OLIVEIRA; JORGE, 2017).

\section{Considerações finais}

A análise dos advérbios e adverbiais de tempo e aspecto revela a impossibilidade de abordar o problema através de categorias estanques. Ao contrário, uma análise que se pretenda eficiente deve partir do contexto de ocorrência das formas adverbiais, se quiser depreender o tipo de relação que elas tecem.

Assim, ao se rotularem os advérbios como de um determinado tipo, como no caso, por exemplo, dos de tempo e aspecto, deve-se considerar as possibilidades interpretativas, que, como demonstrado, podem ser variadas. Este trabalho focalizou três possibilidades de interpretação para a configuração semântica dos advérbios e adverbiais de tempo (referência temporal determinada; dêitico e localização temporal definida do evento) e quatro possibilidades para os de aspecto (duração do evento; quantificação temporal; caráter reiterativo e frequência de ocorrência do evento). Contudo, o analista poderá considerar outras tantas, pois o que vai determinar o processo interpretativo é a natureza do corpus investigado.

Viu-se, também, que as funções dos circunstanciadores centrados nos aspectuais extrapolam os limites estritamente gramaticais. O ingrediente de foricidade (CASTILHO et 
al., 2014) presente em alguns elementos do conjunto faz com que tais elementos exerçam função coesiva nos textos.

A problemática dos advérbios e adverbiais de tempo e aspecto é extremamente complexa. Neste trabalho, buscou-se descomplexificar um pouco a questão, demonstrando algumas das configurações sintáticas e semânticas, bem como relações em um nível linguístico superior ao da sentença, que o grupo pode assumir em textos com sequências predominantemente narrativas.

\section{Referências}

AUROUX, S. A revolução tecnológica da gramatização. Campinas: Unicamp, 1992.

CASTILHO, A. T. Nova Gramática do Português Brasileiro. São Paulo: Editora Contexto, 2010.

CASTILHO, A. T. et al. O advérbio. In: ILARI, R. Gramática do português culto falado no Brasil: volume III: palavras de classe aberta. São Paulo: Contexto, 2014. p. 267-343.

CEZARIO, M. M. Ordenação de advérbios temporais e aspectuais no português escrito: uma abordagem histórica. Rio de Janeiro: Projeto entregue à Pós-Graduação da UFRJ, 2002.

CUNHA, C.; CINTRA, L. Nova Gramática do português contemporâneo. 4. Ed. Rio de Janeiro: Lexikon Editora Digital, 2007.

FERNANDES, Y. 10 relatos que mostram a importância de criminalizar a lgbtfobia. Projeto Colabora, 13 fev. 2019. Disponível em: https://projetocolabora.com.br/ods5/relatos-paraentender-por-que-brasil-deve-criminalizar-lgbtfobia/. Acesso em: 20 abr. 2019.

GIUSTI, I. 20 histórias reais que mostram que agressões psicológicas sofridas por gays são tão traumáticas quanto as Físicas. Buzzfeed Brasil, 06 out. 2014. Disponível em: https://www.buzzfeed.com/br/irangiusti/situacoes-que-lgbts-passam-e-mostram-quehomofobia-vai-alem. Acesso em: 20 abr. 2019.

HAUY, A. B. Gramática da língua portuguesa padrão. 2. ed. São Paulo: Edusp, 2015.

HOPPER, P. On some principles of gramaticalization. In: TRAUGOTT, E. C.; HEINE, B. Approaches to gramaticalization. Amsterdã: John Benjamins, 1991. p. 17-35.

LOPES, C. R. et al. Os advérbios: aspectos históricos e usos atuais. In: LOPES, C. R. Mudança sintática das classes de palavras: perspectiva funcionalista. São Paulo: Contexto, 2018. p. 242-406.

MARTELOTTA, M. E. Ordenação dos advérbios qualitativos nas cartas a Rui Barbosa. Rio de Janeiro: UFRJ, 2009. 
MARTELOTTA, M. E. Advérbios - conceito e tendências de ordenação. In: OLIVEIRA, M. R.; CEZARIO, M. M. (Orgs.). Adverbiais: aspectos gramaticais e pressões discursivas. Niterói: Editora da UFF, 2012. p. 13-96.

MEIER, H. Ensaios de filologia românica. 2. Ed. Rio de Janeiro: Grifo, 1973.

NEVES, M. H. M. A vertente grega da gramática tradicional. São Paulo: Hucitec, 1987.

NEVES, M. H. M. Gramática de usos do português. São Paulo: Editora Unesp, 2000.

NEVES, M. H. M. A gramática passada a limpo: conceitos, análise e parâmetros. São Paulo: Parábola Editorial, 2012.

OLIVEIRA, G.; JORGE, T. Basta de homofobia: relatos de gay, lésbica, bi, trans e travesti no esporte. Globo Esporte, Fortaleza, 19 jun. 2017. Disponível em:

https://globoesporte.globo.com/ce/noticia/basta-de-homofobia-relatos-de-gay-lesbica-bi-transe-travesti-no-esporte.ghtml. Acesso em: 20 abr. 2019.

PEROBELLI, A. Homossexuais relatam agressões e preconceitos e dizem: "não esqueceremos". Uol, São Paulo, 16 jun. 2016. Disponível em:

https://noticias.uol.com.br/cotidiano/listas/homossexuais-relatam-agressoes-e-preconceitos-edizem-nao-esqueceremos.htm. Acesso em: 20 abr. 2019.

ROCHA LIMA, C. H. Gramática normativa da língua portuguesa. 38 ed. Rio de Janeiro: José Olympio, [1957]2000.

SOARES, B.; CEZARIO, M. M. Ordem de sintagmas preposicionais com valor temporal em textos jornalísticos. Diacritica, p. 226-247, 2012.

TRAVAGLIA, L. C. O aspecto verbal no português: a categoria e sua expressão. 3 ed. Uberlândia: Ed. Universidade Federal de Uberlândia, 1994.

VIEIRA, F. E. A gramática tradicional: história crítica. São Paula: Parábola, 2018.

\section{Sobre os autores}

Jhonathan Leno Reis França Santana (Orcid iD: http://orcid.org/0000-0002-4031-4034)

Mestrando do Programa de Pós-Graduação em Linguística da Universidade Federal do Espírito Santo (UFES); licenciado em Língua Portuguesa e Literaturas de Língua Portuguesa pela mesma instituição. Bolsista da FAPES.

Gesieny Laurett Neves Damasceno (Orcid iD: http://orcid.org/0000-0001-6556-9968)

Doutora em Letras Vernáculas (Língua Portuguesa) pela Universidade Federal do Rio de Janeiro (UFRJ); mestra em Estudos Linguísticos pela Universidade Federal do Espírito Santo (UFES); graduada em Língua Portuguesa e Literatura de Língua Portuguesa pela mesma instituição. É professora do Departamento de Línguas e Letras e do Programa de Pós-Graduação em Linguística da UFES.

Recebido em junho de 2020.

Aprovado em setembro de 2020. 